\title{
Modelling of Global Solar Radiation in Algeria Based on Geographical and all Climatic Parameters
}

\author{
Sabah FETAH $^{1}$, Mohamed SALMi ${ }^{2}$ \\ ${ }^{1}$ Department of Physics, Faculty of science. University of M'sila, 28000, Algeria \\ * Corresponding Author : Email: sabah.fetah@ univ-msila.dz - ORCID: 0000-0001-8483-7016 \\ ${ }^{2}$ Department of Physics, Faculty of science. University of M'sila, 28000, Algeria \\ Email: mohamed.salmi@univ-msila.dz - ORCID: 0000-0002-4146-3592
}

\section{Article Info:}

DOI: $10.22399 /$ ijcesen.1018844

Received : 01 October 2021

Accepted : 07 November 2021

\section{Keywords :}

Global solar radiation

Modelling

Statistical regression

Geographical parameters

Climatic parameters

\begin{abstract}
:
The design of photovoltaic or solar systems and estimating their performance require knowledge of the intensity of solar radiation. The measurement of this parameter for some sites in Algeria is unfortunately not obvious. However, researchers are moving towards the modelling, estimation and prediction. To model the global solar radiation, we must take into account the geographical and climatic parameters such as sunshine duration, relative humidity, temperature, latitude site, etc. In this study, the modelling of daily global solar radiation on a horizontal plane according to the parameters mentioned above is based on the statistical linear regression technique. The daily data used in the development and validation of models are extracted from the database of O. N. M (National Office of Meteorology, Dar el Beida. Algeria) for 2001-2005. We test the proposed models on two sites such as Djelfa and Ain-Bessam. For each site, validity and performance of the model will be studied based on the number of parameters introduced in the analytical expressions and results are discussed in terms of statistical errors as: R, MBE and RMSE between the measured global solar radiation and global solar radiation estimated. It was found that air temperature and relative humidity are indeed important climatic parameters for the prediction of solar radiation.
\end{abstract}

\section{Introduction}

Solar energy is the most ancient source of energy; it is the basic element for almost all fossil and renewable types. Using solar energy to generate electrical energy for any specific site location necessitates an exact estimation of global solar radiation; a provision should be made to forecast solar energy which will convert to electrical energy to recover the load demand, that is, the amount of solar energy for that place ought to be known. Technology for measuring global solar radiation is costly and has instrumental hazards. The importance of the actual work lies on the fundamental need of quantification of the global solar radiation data in this site. The solar radiation reaching the earth's surface depends on the climatic condition of the specific site location [1-3]. Therefore, over the last decades, different models have been proposed to predict the amount of solar radiation using various parameters. Most analyses of the correlation between solar radiation and climatic parameters involve the use of relative sunshine duration [4-7]. However, air temperature and humidity should also be considered as an important climatic variable for solar radiation prediction because it is a reflection of both the duration and intensity of the solar radiation incident on a given location $[8,9],[10-12]$.

\section{Data}

Measured global solar irradiation (G) and climatic parameters data, between 2001 and 2005, for two cities in Algeria: Ain-Bessem (Latitude $36.31^{\circ} \mathrm{N}$, Longitude $3.67^{\circ} \mathrm{E}$, Altitude $629(\mathrm{~m})$ ) and Djelfa (Latitude $34.68^{\circ} \mathrm{N}$, Longitude $3.25^{\circ} \mathrm{E}$, Altitude 1126 (m)), were obtained from Algerian Meteorological Agency O.N.M, Dar el Beida. Our aim is to develop a best model with a few climatic parameters to estimate the solar radiation data $(\mathrm{G} / \mathrm{G} 0)$ in future time domain. The estimations 
were made by many combinations of data, by using a linear regression analysis. These data are chosen due to their correlation with the global solar radiation. In linear regression model, the dependent variable comprises the ratio of the global solar irradiation $(\mathrm{G})$ to the available radiation at the top of the atmosphere (G0); and the independent variables comprise the different climatic parameters (mean daily maximum temperature, mean daily relative humidity, mean daily sea level pressure, mean daily vapor pressure, wind, precipitation and the ratio of hours of bright sunshine (S) to the day length (S0). The measured data between 2001 and 2004 have been used for calculating the coefficients of the model while those from 2005 are used for testing data. The testing data are not used in modeling. The values of the extraterrestrial radiation $\mathrm{G} 0$ and the day length $\mathrm{S} 0$ were calculated. The data was subjected to quality checks before being used in the analysis. It was ensured only complete data set was used. The values of G/Go and $\mathrm{S} / \mathrm{So}$ are all less than one.

\section{Discussions}

The choice of a number of models is conducted by the fact that the single model does not give a good generalization for the sites under study. Accordingly, several models have been tested to choose the more suitable for each location. Statistical analysis of the results was performed using the correlation coefficient (R), the root mean square error (RMSE) and the mean bias error (MBE) criteria $[12,13]$.

Table 1. Pearson's correlation coefficients

\begin{tabular}{|c|c|c|c|c|c|c|c|c|c|c|c|}
\hline & p & $v$ & $R$ & If & Im & in & Um & $\operatorname{sen}$ & $\pi \pi_{x}$ & $\omega \omega_{x}$ & 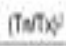 \\
\hline${ }_{B \text { Bestem }}^{\text {An }}$ & 0,64 & 0.307 & .0520 & 0.53 & $\begin{array}{c}0 \text { 年 } \\
1\end{array}$ & 0346 & .0114 & 0,454 & 40068 & .0636 & 0.287 \\
\hline Dith & 0.215 & 0012 & .0272 & 0509 & 0.450 & 0.35 & .0591 & 0.238 & 0516 & .0534 & 0.190 \\
\hline
\end{tabular}

The study of correlations among solar radiation and several climatic parameters has shown that $(\mathrm{S} / \mathrm{So})$ is not the best single parameter to be used for predicting solar radiation. For example, Table 1 shows Pearson's correlation coefficients for AinBessem and Djelfa cities. It is seen that for AinBessem, (G/Go) correlate best with (Tx), followed by $\mathrm{Tm}$ and S/So, respectively, while (Um) and (Tx) are best followed by Tm for Djelfa. Thus in both cases, the best single parameter for estimating $(\mathrm{G} / \mathrm{Go})$ is not $(\mathrm{S} / \mathrm{So})$. From Table 3, we can observe that the correlation coefficient for the studied models, listed presented in Table 2, is arranged between $72.30 \%$ and $91.00 \%$. It is clearly shown that, the best performance is obtained by the models $(7,8,9$ and10) where the correlation coefficient $\mathrm{R}$ is arranged between $90.30 \%$ and $91.10 \%$.

Table 2. Models used for estimating (G/G0) for AinBessem city.

\begin{tabular}{|c|c|}
\hline Models & Ain Bessem \\
\hline 1 & $\mathrm{G} / \mathrm{GO}=0.2597+0.103(\mathrm{Tx})$ \\
\hline 2 & $\mathrm{G} / \mathrm{GO}=0.142+0.069(\mathrm{Tx})-0.075(\mathrm{Tm})$ \\
\hline 3 & $\mathrm{G} / \mathrm{G} 0=0.1621+0.0352(\mathrm{Tx})-0.0418(\mathrm{Tn})$ \\
\hline 4 & $\mathrm{G} / \mathrm{GO}=0.152+0.046(\mathrm{Tx})-0.021(\mathrm{Tm})-0.031(\mathrm{Tn})$ \\
\hline 5 & $\mathrm{G} / \mathrm{G} 0=0.4365+0.0305(\mathrm{Tx})-0.0312(\mathrm{Tn})-0.3924(\mathrm{Tm} / \mathrm{Tx})$ \\
\hline 6 & $\begin{aligned} \mathrm{G} / \mathrm{GO}= & 0.7152+0.077(\mathrm{Tx})-0.0294(\mathrm{Tn})-0.4701(\mathrm{Tm} / \mathrm{Tx}) \\
& -0.2372(\mathrm{Um} / \mathrm{Ux})\end{aligned}$ \\
\hline 7 & $\begin{aligned} \mathrm{G} / \mathrm{G} 0= & 0.6740+0.0238(\mathrm{Tx})-0.0266(\mathrm{Tn})-0.3743(\mathrm{Tm} / \mathrm{Tx}) \\
& -0.3503(\mathrm{Um} / \mathrm{Ux})+0.0001(P)\end{aligned}$ \\
\hline 8 & $\begin{aligned} \mathrm{G} / \mathrm{GO}= & 0.6855+0.0219(\mathrm{Tx})-0.0244(\mathrm{Tn})-0.3357(\mathrm{Tm} / \mathrm{Tx}) \\
& -0.4033(\mathrm{Um} / \mathrm{Ux})+0002(\mathrm{P})-0.0051(\mathrm{Vx})\end{aligned}$ \\
\hline 9 & $\begin{aligned} \mathrm{G} / \mathrm{GO}= & 0.6731+0.0216(\mathrm{Tx})-0.0242(\mathrm{Tn})-0.3326(\mathrm{Tm} / \mathrm{Tx}) \\
& -0.3851(\mathrm{Um} / \mathrm{Ux})+0.0002(\mathrm{P})-0.0042(\mathrm{Vx})-0.0034(\mathrm{R})\end{aligned}$ \\
\hline 10 & $\begin{aligned} \mathrm{G} / \mathrm{G} 0= & 0.5707+0.0004(\mathrm{P})-0.0046(\mathrm{Vx})-0.0028(\mathrm{R})+0.0257(\mathrm{Tx}) \\
& -0.0202(\mathrm{Tn})-0.0116(\mathrm{Tm})-0.2817(\mathrm{Tm} / \mathrm{Tx})-0.2905(\mathrm{Um} / \mathrm{Ux}) \\
& -0.0026(\mathrm{Um})\end{aligned}$ \\
\hline
\end{tabular}

However, the best correlation in test is obtained for the model 7, and this model need in his input only $(\mathrm{T}, \mathrm{U})$ parameters and $\mathrm{P}$ that are always available, and they can be measure easily. The obtained R is $95.20 \%$, which is higher than other models. The RMSE is 0.032799 and the MBE is -0.034701 . Figure1 shows a comparison between measured and estimated daily global solar radiation by using model 7. In addition, we have developed others models for Djelfa city, where the relative humidity is always combined with temperature. Therefore, we develop these models in order to show the influence of each parameter for estimating daily global solar radiation. Table 4 resumes the different models used for estimating (G/G0) for Djelfa city. Therefore, in the case, when we use as input only the relative humidity and temperature, the best correlation coefficient is decreases to $79.10 \%$ (model 11).

Table 3. Statistical analysis of the results. The correlation coefficient $(R)$, the root mean square error (RMSE) and the mean bias error (MBE)

\begin{tabular}{|c|c|c|c|c|}
\hline \multirow[b]{2}{*}{ Wudet } & \multirow[b]{2}{*}{$\pi$} & \multicolumn{3}{|c|}{ 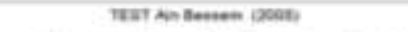 } \\
\hline & & $*$ & mate & $s=$ \\
\hline 1 & aras & a Mascose? & govasinit & 6200014 \\
\hline 3 & Smate & adversen & 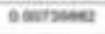 & ochan \\
\hline 5 & enese & e navorieson & exosizes & armase \\
\hline 6 & mense & esceseront & scositass & taxpe: \\
\hline 7 & suche & eantasurn: & a asmos & 60067 \\
\hline 8 & saens & exabeana & Q ansatane & aseana \\
\hline 9 & anese & exarataves & Q e.cosisat & QDavisa \\
\hline 10 & ente & enacosone & ocascasins & Q easma \\
\hline
\end{tabular}




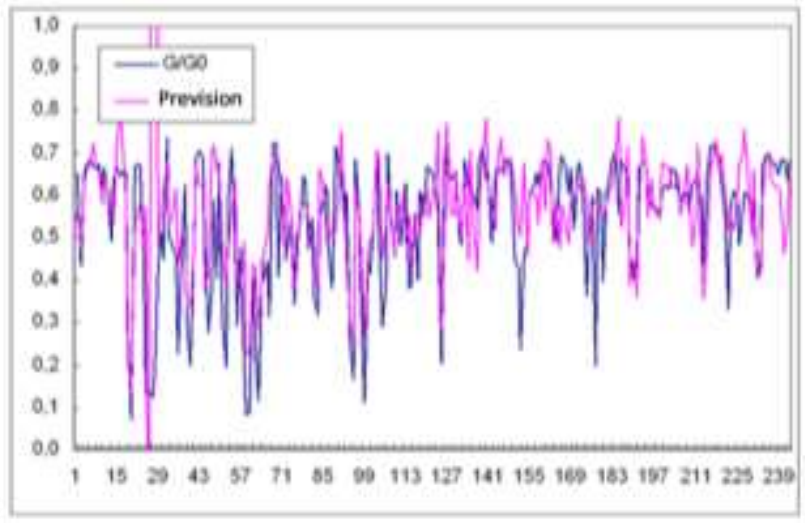

Figure1. comparison between measured and estimated daily global solar radiation by using model 7 (AinBessem).

Table 4. Models used for estimating for Djelfa city

\begin{tabular}{|c|c|c|}
\hline Model & R & Diota \\
\hline 1 & 0.501 & GCO $0.08670 \cdot 0.0037(\mathrm{~N}=1$ \\
\hline 2 & $0.69 t$ & 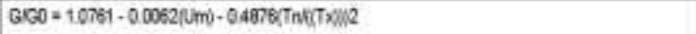 \\
\hline 3 & 0.711 & 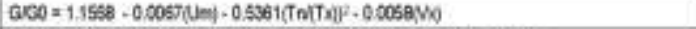 \\
\hline 4 & 0.719 & 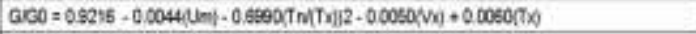 \\
\hline 5 & 0.729 & 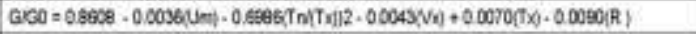 \\
\hline a & 0.785 & 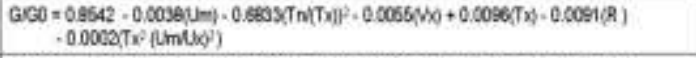 \\
\hline 7 & 0.766 & 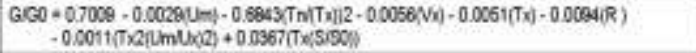 \\
\hline 6 & $0 . \pi 7$ & 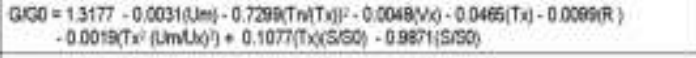 \\
\hline 9 & 0.794 & 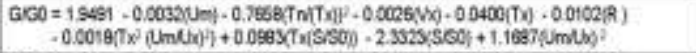 \\
\hline 10 & 0.802 & 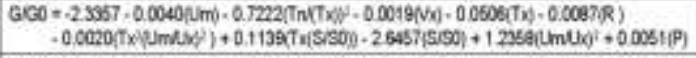 \\
\hline$\pi$ & 0.791 & 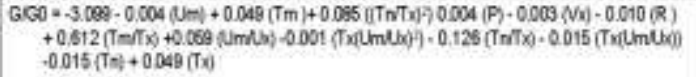 \\
\hline
\end{tabular}

Also, when we mixed air temperature, relative humidity and the ratio S/S0 the correlation coefficient is decreases only to $80.20 \%$ (model 10 ). Therefore, the model combined ( $\mathrm{T}$ and $\mathrm{U}$ ) can be used in the case when we have not the sunshine duration. Figure 2 shows a comparison between measured and estimated daily global solar radiation by using model 11 . It is clear that air temperature and relative humidity are indeed important climatic parameters for the prediction of solar radiation.

\section{Conclusions}

Using different combinations of different variables to analyse available data for two different stations in Algeria, it is clearly demonstrated that air temperature and humidity are an important climatic parameters which should be sufficient in solar radiation modelling in Algeria. The use of only temperature and relative humidity for solar radiation prediction is important because there are many stations in Algeria with sufficient data for $\mathrm{T}$ and $\mathrm{U}$ (which are relatively easier to measure).

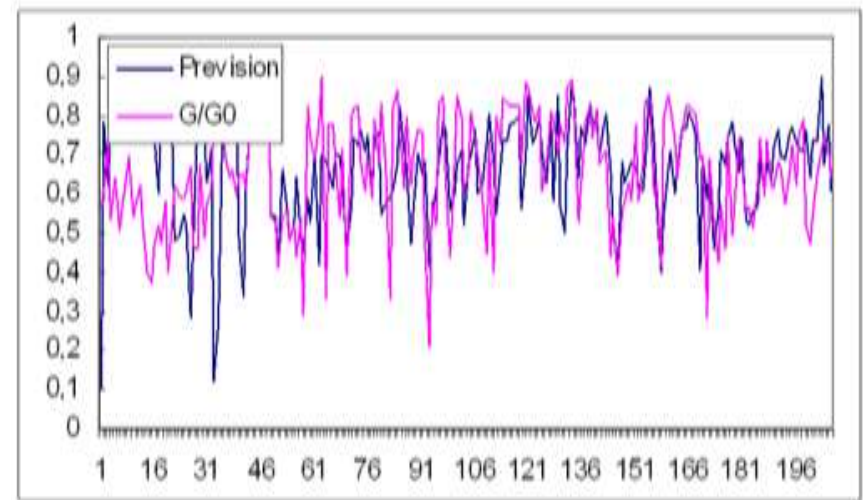

Figure 2. comparison between measured and estimated daily global solar radiation by using model 11 (Djelfa).

\section{Author Statements:}

- The authors declare that they have equal right on this paper.

- The authors declare that they have no known competing financial interests or personal relationships that could have appeared to influence the work reported in this paper

- The author would like to thank the Algerian Meteorological Agency for providing data for achieving the present work.

\section{References}

[1] J. A. Prescott, "Evaporation from a water surface in relation to solar radiation". Trans. R. Soc. Sci. Austria 46, (1940) 114-118

[2] S. M Robaa, "Validation of the existing models for estimating global solar radiation over Egypt". Energ. Convers. Mgmt. 50, (2009)184-193.

[3] K.Skeiker, "Correlation of global solar radiation with common geographical and meteorological parameters for Damascus province, Syria”. Energy Convers. Mgmt. 47,( 2006)331-345.

[4] J.Almorox, C.Hontoria, "Global solar estimation using sunshine duration in Spain". Energ. Convers. Mgmt. 45 , (2004)1529-1535.

[5] D. B.Ampratwum, and A. S. S. Dorvlo, "Estimation of solar radiation from the number of sunshine hours" App. Energ. 63(1999),161-167.

[6] R.Kumar and L. R.Umanand, "Estimation of global radiation using clearness index model for sizing photovoltaic system". Renew. Energ. 30, (2005)2221-2233.

[7] E-M. Mossad, "Sunshine and global solar radiation estimation at different sites in Egypt". J. Atmos. and Sol-Terr. Phy. 67, (2005)1331-1342.

[8] B. G.Akinoglu and A.Ecevit, "Construction of a quadratic model using modified Angström coefficients to estimate global solar radiation". Sol. Energy 45,(1990)85-92.

[9] A. Al-Mohamed, "Global, direct and diffuse solar radiation in Syria”. Appl. Energ. 79,(2004)191-200. 
[10] A.A.El-Sebaii and A.A.Trabea, "Estimation of global solar radiation on horizontal surfaces over Egypt”. Egypt. J. Solids 28(2005)163-175.

[11] N. A Elagib and M. G Mansell. "New approaches for estimating global solar radiation across Sudan". Energ. Convers. Mgmt. 41(2000)419-434.

[12] O.Galip, H. Arif and G.Asir, "Statistical analysis of solar radiation data". Energ. Source. 25(2003), 1089-1097.

[13] J.Almorox, M.Benito, and C.Hontoria, "Estimation of monthly Angström-Prescott equation coefficients from measured daily data in Toledo", Spain. Renew. Energ. 30,( 2005) 931-936. 